\title{
Relationship between expansion of the myocardial interstitial space and ventricular performance in patients with pulmonary hypertension
}

\author{
Elena Pena ${ }^{1,2^{*}}$, Rebecca E Thornhill ${ }^{1,2}$, Lin Yassin Kassab ${ }^{3}$, Carole Dennie ${ }^{1,2}$, Girish Dwivedi ${ }^{4}$, Alexander Dick ${ }^{4}$, \\ Lisa Mielniczuk ${ }^{4}$
}

From 19th Annual SCMR Scientific Sessions

Los Angeles, CA, USA. 27-30 January 2016

\section{Background}

Diffuse interstitial fibrosis is a common end point in heart failure from multiple etiologies. The post contrast T1 time, extracellular volume (ECV) and partition coefficient $(\lambda)$ of gadolinium-based contrast media have been used to estimate expansion of myocardial interstitial space, as a surrogate of interstitial fibrosis. The aim of the study was to explore the relationship between T1-based estimates of interstitial expansion and both right (RV) and left (LV) ventricular functional parameters in pulmonary hypertension $(\mathrm{PH})$.

\section{Methods}

We prospectively recruited 8 patients with a diagnosis of $\mathrm{PH}$ (pulmonary arterial hypertension, $\mathrm{n}=5$; chronic thromboembolic pulmonary hypertension, $n=3$ ) who underwent CMR at 3T. CMR studies included functional (bSSFP) cine imaging for assessment of ventricular function. Phase contrast velocity encoded cine imaging was obtained perpendicular to the main pulmonary artery for RV stroke volume assessment. T1 maps (saturation recovery single-shot acquisition (SASHA) were acquired both pre- and 15 minutes after administration of $0.2 \mathrm{mmol} / \mathrm{kg}$ of Gadobutrol. For each patient, a blood sample was acquired prior to scanning to evaluate hematocrit. Whole-LV as well as septal values of postcontrast T1, ECV and $\lambda$ were evaluated offline. The relationships between each T1-based estimate and functional parameters were investigated using Spearman's rank correlation (rho).

\section{Results}

Significant positive correlations were found between septal post contrast T1 time and RV stroke volume indexed (RVSVI) (rho $=0.86, \mathrm{p}=0.007)$ and between $\lambda$ and $\mathrm{RV}$ end-diastolic volume indexed (RVEDVI) (rho $=0.74$, $\mathrm{p}=0.04)$ as well as between whole-LV post contrast $\mathrm{T} 1$ times and LV ejection fraction (LVEF) (rho=0.83,p=0.04). There were no significant correlations between ECV values and any functional parameters ( $p>0.05$ for each).

Trends towards positive correlations between whole-LV post-contrast $\mathrm{T} 1$ and $\mathrm{LV}$ stroke volume indexed (rho $=0.69, \mathrm{p}=0.06)$, RVSVI $(\mathrm{rho}=0.62, \mathrm{p}=0.10)$ and RV ejection fraction $(\mathrm{rho}=0.60, \mathrm{p}=0.12)$, and towards negative correlations with RV end systolic volume indexed $(\mathrm{rho}=-0.60, \mathrm{p}=0.12)$ were found. There was also a trend towards positive correlation between septal post contrast T1 and LVEF (rho $=0.60, \mathrm{p}=0.12$ ). Furthermore, trends toward negative correlations between septal $\lambda$ and both $\mathrm{RV}$ stroke volume (rho $=-0.62, \mathrm{p}=0.10)$ and $\mathrm{RV}$ cardiac output $(\mathrm{rho}=-0.60, \mathrm{p}=0.12)$ were revealed.

\section{Conclusions}

$\lambda$ increases with dilatation of the RV and shorter post contrast $\mathrm{T} 1$ times are seen in patients with increased RV end diastolic volumes and decreased stroke volumes, as well as lower LVEF reflecting a link between diffuse interstitial fibrosis and biventricular functional impairment. Post contrast $\mathrm{T} 1$ times and $\lambda$ may be non-invasive biomarkers of increased interstitial fibrosis seen in maladaptive stages of the disease when progressive dilatation of the RV results in RV systolic dysfunction leading to impairment of LV filling.

${ }^{1}$ Medical Imaging, The Ottawa Hospital, Ottawa, ON, Canada

Full list of author information is available at the end of the article 


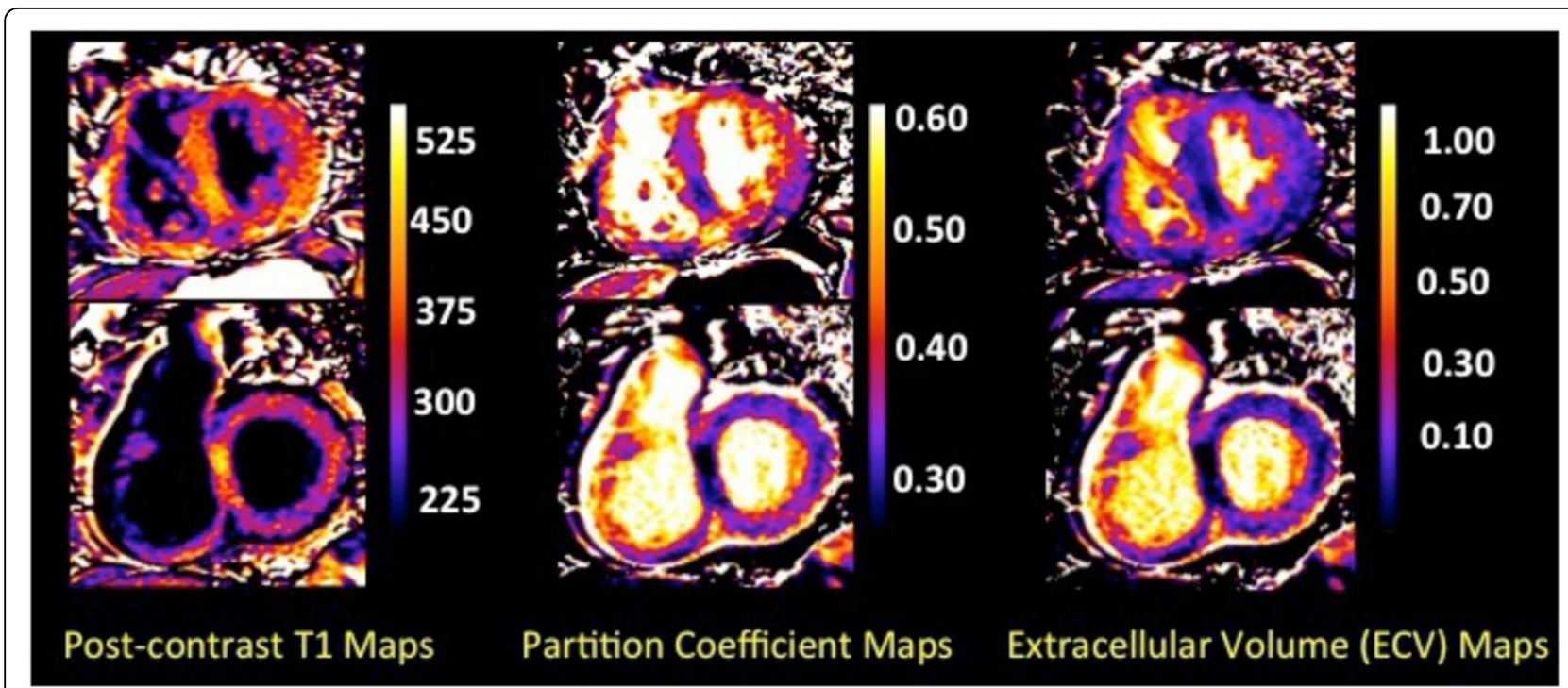

Figure 1 Post contrast T1, partition coefficient and extracellular volume maps in a patient with pulmonary hypertension.

\section{Authors' details}

'Medical Imaging, The Ottawa Hospital, Ottawa, ON, Canada. ${ }^{2}$ Radiology, University of Ottawa, Ottawa, ON, Canada. ${ }^{3}$ Carleton University, Ottawa, ON, Canada. ${ }^{4}$ Division of Cardiology, Department of Medicine, University of Ottawa Heart Institute, Ottawa, ON, Canada.

Published: 27 January 2016

doi:10.1186/1532-429X-18-S1-P291

Cite this article as: Pena et al:: Relationship between expansion of the myocardial interstitial space and ventricular performance in patients with pulmonary hypertension. Journal of Cardiovascular Magnetic Resonance 2016 18(Suppl 1):P291.
Submit your next manuscript to BioMed Central and take full advantage of:

- Convenient online submission

- Thorough peer review

- No space constraints or color figure charges

- Immediate publication on acceptance

- Inclusion in PubMed, CAS, Scopus and Google Scholar

- Research which is freely available for redistribution 